\title{
Editorial
}

\section{Christian Christodoulou}

Senior Transport Executive - Director Bridges \& Structures, Transport for New South Wales, Sydney, Australia

\section{Mohammad M. Kashani}

Associate Professor, University of Southampton, Faculty of Engineering and the Environment, Southampton, UK
Transport infrastructure plays a crucial role in economic and societal growth, productivity and quality of life. The total value of road infrastructure in Great Britain is estimated to be $£ 227$ billion, whereas that of the rail network is estimated to be worth $£ 336$ billion. However, asset life varies considerably, with some parts of the networks still fundamentally relying on Victorian infrastructure to service modern needs.

Bridges and structures may deteriorate as a result of a variety of contributing mechanisms, which may be chemical, mechanical or material related, such as alkali-silica reaction, fatigue, sulphate attack and so on, with corrosion being the most common.

For concrete bridges, corrosion of the reinforcement leads to severe damage through cracking and spalling of the concrete cover, reduction in strength (flexural, shear, etc.), reduction in ductility of reinforcement and pre-stressing tendons, and reduction of bond strength between steel and concrete.

This themed issue invited topics covering impact of material deterioration on structural performance of bridges and structures, assessment methodologies of bridges subject to varying deterioration mechanisms, performance-based assessment methodologies, experimental testing methods of deteriorated bridge components, probabilistic methods for modelling uncertainties in material deterioration and extreme loading and others. The papers featured in this issue of Bridge Engineering focus on condition and structural evaluation, experimental testing and load effects, with descriptions of current practice in the UK, Middle East, Italy and USA demonstrating international experience.

The paper by Christodoulou and Dodds (2022) presents a case study of the condition evaluation, structural assessment and durability analysis of the Al Maktoum bridges in the United Arab Emirates to provide scientific evidence and technical assurance that the in-service bridges will meet their intended 100 -year service life and associated load-carrying capacities as they currently stand.
The paper by Neppmuceno et al. (2022) is a research article that utilises thermal data from a year-long comprehensive monitoring programme on Waterloo Bridge in London, UK to compare them with values obtained theoretically from design models covering Eurocodes (BS EN 1001-1-5), AASHTO and New Zealand codes of practice.

The paper by Karthik et al. (2022) utilises the evidence of alkali-silica reaction and delayed ettringite formation on bridge piers in Texas, USA and used a semi-empirical expansion model to assess the deleterious effects of such deterioration on the load-bearing capacity. It was determined that although there was an increase in strains, the piers still had sufficient reserve capacity for their intended purposes.

The paper by Belleti and Vecchi (2022) discusses the development of a fixed crack model, which is implemented as a subroutine in standard finite-element software to assess seismic response and failure mode of reinforced concrete elements subject to corrosion. The model's effectiveness was validated by comparison to experimental data available in the literature.

\section{REFERENCES}

Belletti B and Vecchi F (2022) A crack model for corroded reinforced concrete elements subject to cyclic loading. Proceedings of the Institution of Civil Engineers - Bridge Engineering 175(1): 50-65, https://doi.org/10.1680/jbren.20.00044.

Christodoulou C and Dodds W (2022) Al Maktoum bridges, UAE: condition evaluation, assessment and durability analysis. Proceedings of the Institution of Civil Engineers - Bridge Engineering 175(1): 2-15, https://doi.org/10.1680/jbren.19.00056.

Treasury HM (2020) Whole of Government Accounts. See https://www.gov.uk/government/collections/whole-of-governmentaccounts (accessed 28/01/2022).

Karthik MM, Mander JB and Hurlebaus S (2022) Alkali-silica reaction, delayed ettringite formation and corrosion effects on a bridge pier. Proceedings of the Institution of Civil Engineers - Bridge Engineering 175(1): 35-49, https://doi.org/10.1680/jbren.20.00031. Nepomuceno DT, Webb GT, Bennetts J, Tryfonas T and Vardanega PJ (2022) Thermal monitoring of a concrete bridge in London, UK. Proceedings of the Institution of Civil Engineers - Bridge Engineering 175(1): 16-34, https://doi.org/10.1680/jbren.20.00012. 